\title{
Contaminação de profissionais e acadêmicos no centro cirúrgico de um Hospital Universitário após higienização das mãos
}

\author{
Contamination of professionals and academics in the surgical center of a University Hospital after \\ hand hygiene
}

Altair Paulino de Oliveira Campos ${ }^{\dagger}$, Gabriel Porto Soares ${ }^{\ddagger}$, Saulo Roni Moraes ${ }^{\ddagger}$, Maria Cristina Almeida de Souza ${ }^{* *}$

Como citar esse artigo. Campos,

A.P.O.; Soares, G.P.; Moraes, S.R.; de Souza, M.C.A. Contaminação de profissionais e acadêmicos no centro cirúrgico de um Hospital Universitário após higienização das mãos. Revista de Saúde. 2019 Jul./Dez; 10 (2): 26-30.

\begin{abstract}
Resumo
Introdução: embora a higienização das mãos seja a medida mais importante e reconhecida há muitos anos na prevenção no controle das infecções nos serviços de saúde, colocá-la em prática consiste em uma tarefa complexa e difícil. Objetivo: avaliar a contaminação, após higienização das mãos, dos profissionais que atuam no centro cirúrgico do Hospital Universitário de Vassouras (HUV). Metodologia: tipo transversal e observacional. Após higienização das mãos, foi solicitado aos profissionais e acadêmicos que realizasse a impressão da palma de uma das mãos, interdigital e unhas em Swab. O material coletado foi colocado em placa de Petri e levado a estufa para verificação do crescimento bacteriano. Resultados: foram coletadas 67 amostras dos profissionais. Foram encontrados 3 diferentes grupos de bactérias: Grupo Staphylococcus coagulase negativo (SCoN), Staphylococcus aureus e Bacilos gram negativo com predominância de maior contaminação no grupo dos médicos ortopedistas e acadêmicos, e menor contaminação no grupo de enfermeiros. Considerações finais: a técnica de higienização das mãos não foi realizada de modo eficaz.

Palavras-chave: Desinfecção das Mãos, Hospital, Infecção hospitalar, Serviços de saúde.
\end{abstract}

\begin{abstract}
Introduction: although hand hygiene is the most important and recognized measure for many years in preventing infection in health services, putting it into practice is a complex and difficult task. Objective: evaluate the contamination after sanitization of the hands of the professionals who work in the surgical center of the University Hospital of Vassouras (HUV). Methodology: was transversal and observational. After hand hygiene, professionals and academics were asked to perform the printing of the palm of one hand, interdigital and fingernails on Swab. The collected material was placed in Petri dish and taken to the greenhouse for bacterial growth. Results: a total of 67 samples were collected from the professionals. Three different groups of bacteria were found: Staphylococcus coagulase negative (SCoN), Staphylococcus aureus and Gram negative bacilli with predominance of greater contamination in the group of orthopedic and academic physicians, and lower contamination in the group of nurses. Conclusion: it was concluded that the technique of hand hygiene was not performed effectively.
\end{abstract}

Keywords: Hands Desinfection, Hospital, Cross infection, Health services.

\section{Introdução}

A higienização das mãos, anteriormente denominada lavagem das mãos, é a medida individual mais simples e menos onerosa para prevenir a proliferação das infecções1. Não obstante, grande parte das infecções acontece pela não adesão a essa medida de controle devido à desmotivação e pouca importância a ela dada ${ }^{2,3,4}$.

Em 1989, o Ministério da Saúde editou o manual "Lavar as mãos" com o objetivo de normatizar esse procedimento. Estudos têm mostrado a importância da lavagem das mãos na redução das taxas de infecções hospitalares. As infecções do sitio cirúrgico estão entre as infecções associadas aos cuidados de saúde mais evitáveis e causam custos adicionais ao sistema de saúde ${ }^{5,6}$.

No Brasil, o controle de infecções hospitalares começou a ser aprimorado por meio da Portaria 2616/98 que determina que os hospitais mantenham um Programa de Controle Infecções Hospitalares (PCIH) e criem uma Comissão de Controle de Infecções Hospitalares (CCIH). A legislação brasileira, por meio da Resolução da Diretoria Colegiada da Agência Nacional de Vigilância Sanitária (RDC-ANVISA) 50/2002, estabelece as ações mínimas a serem desenvolvidas com vistas à redução da incidência das infecções relacionadas à assistência a saúde ${ }^{6,7}$.

Em 2011, a ANVISA publicou a RDC no. 63,

Afiliação dos autores: † Mestrado em Ciências Aplicadas em Saúde. Discente. Universidade de Vassouras. Vassouras/RJ, Brasil

\$ Mestrado em Ciências Aplicadas em Saúde. Universidade de Vassouras. Docente. Vassouras/RJ, Brasil

*Email de correpondência: mcas.souza@uol.com.br 
que dispõe sobre os requisitos de boas práticas de funcionamento para os serviços de Saúde. O artigo $8^{\circ}$ desta resolução define que o serviço de saúde deve estabelecer entre as ações voltadas à Segurança do Paciente, a estratégia multimodal de melhoria da higienização das mãos que engloba cinco componentes: mudança no sistema, capacitação e educação, avaliação e devolução, lembretes no local de trabalho e clima institucional seguro. Sendo assim, a prevenção e o controle dessas infecções dependem, dentre outras medidas, da adesão e da motivação do profissional de saúde em lavar correta e frequentemente as mãos ${ }^{8,9}$.

O objetivo desse artigo é avaliar a contaminação após higienização das mãos de médicos, enfermeiros e também de acadêmicos de medicina da Universidade de Vassouras no centro cirúrgico do Hospital Universitário de Vassouras (HUV).

\section{Materiais e Métodos}

Trata-se de pesquisa transversal e observacional aprovada pelo Comitê de Ética em Pesquisa da Universidade Severino Sombra, sob Parecer $\mathrm{n}^{\circ}$. 1.758.931, de 04/10/2016. Os critérios de inclusão foram o participante atuar na equipe do centro cirúrgico do HUV e concordar em assinar o Termo de Consentimento Livre e Esclarecido.

A amostra foi composta por 67 indivíduos. Os dados foram coletados no período de Agosto/2017 a Março/2018 por um único pesquisador. A coleta do material foi feita em dois momentos: pré e póshigienização das mãos, por meio da impressão em swab, da palma de uma das mãos, da interdigital e das unhas.

As amostras coletadas foram então semeadas em placas de Petri com Agar sangue como meio de cultivo e acondicionadas em estufa à temperatura de $36^{\circ} \mathrm{C}$ por $24 \mathrm{~h}$ avaliação do crescimento bacteriano. A primeira análise do material foi realizada após 24 e a segunda, após 48 horas. Foram consideradas negativas as culturas que não apresentaram crescimento bacteriano após 48 horas. As placas consideradas positivas apresentavam colônias em numero superior a três UFC (unidades formadoras de colônia) analisadas em lupa para contagem de UFCs. As colônias predominantes foram identificadas, inicialmente, realizando coloração de Gram e seguida as colônias foram inoculadas em provas bioquímicas especificas para identificação de espécie utilizando sistema semi-automatizado (MicroScanR) de acordo com as indicações do fabricante.

As placas de Petri foram numeradas eidentificadas de acordo com a categoria do participante a que pertencia o material coletado: se médico (com especialidade), se enfermeiro e se acadêmico de medicina. A amostra foi então dividida em seis grupos. Cinco integrados por profissionais (médicos especialistas e enfermeiros:
Médicos Cirurgiões, Médicos Ortopedistas, Médicos Ginecologistas/Obstetras, Médicos Anestesiologistas, Enfermeiros) e um grupo composto pelos Médicos Residentes e acadêmicos. A análise comparativa entre os grupos de profissionais e o de acadêmicos foi realizada por meio do cálculo da razão de prevalência.

\section{Resultados}

Foram coletadas 24 amostras de Médicos Cirurgiões, seis amostras de Médicos Anestesiologistas, seis amostras de Médicos Ortopedistas, duas amostras de Médicos Ginecologistas/Obstetras, dez amostras de enfermeiros e 19 amostras de Médicos Residentes e de Acadêmicos, totalizando 67 amostras. Conforme tabela destaca-se que mais da metade das oportunidades para a higienização das mãos foram da equipe Médica.

\section{Discussão}

As infecções podem ser classificadas como uma das maiores causas de morte em todas as idades, principalmente entre os membros mais vulneráveis da população. Segundo a Organização Mundial de Saúde (OMS), quanto mais doente está o paciente, maior o risco de adquirir uma Infecção Relacionada à Assistência à Saúde - IRAS. Em todo o mundo, pelo menos um entre quatro pacientes que necessitam de cuidados intensivos adquirem uma infecção durante sua permanência nos hospitais ${ }^{11}$.

As infecções hospitalares infligem altos custos aos doentes e suas famílias como também sobrecarregam financeiramente os sistemas de saúde e contribuem para mortes evitáveis. Já existem práticas simples e de baixo custo para evitar estas infecções. A higienização das mãos continua sendo a principal medida para reduzir as infecções relacionadas à assistência à saúde e a disseminação da resistência microbiana, aumentando a segurança do paciente ${ }^{10}$. Apesar disto, a observância da higienização das mãos ainda é muito baixa em todo o mundo, tornando necessária a promoção desta prática $^{11,12}$.Assim como essa pesquisa, estudo que avaliou a qualidade técnica da higienização das mãos de alunos e medicina e enfermagem observou não foi realizada de modo eficaz. E concluiu que o papel educativo é fundamental para sedimentar as bases de boas práticas na higienização das mãos, em conhecimentos teóricos e no desenvolvimento de habilidades e reforço de boas práticas $^{12}$.

Embora a higienização das mãos seja um procedimento simples e de baixo custo, a negligência dos profissionais em não realizá-la é um problema mundialmente questionado ${ }^{13}$. O Ministério da Saúde afirma que todos os profissionais que trabalham em serviços de saúde, que mantenham contato direto ou 
indireto com os usuários, que atuem na manipulação de medicamentos, alimentos e material estéril ou contaminado, devem adotar em sua prática as recomendações básicas de higienização das mãos ${ }^{11}$.

A redução de infecção hospitalar está ligada a diversos fatores, dentre eles, e o mais importante e barato, é a higienização das mãos, que apesar de não retirar completamente todos os micro-organismos, diminui substancialmente esse número, favorecendo o não surgimento da infecção hospitalar ${ }^{13}$.

Tabela1. Contaminação das mãos após higienização por Médicos Cirurgiões.

\begin{tabular}{|c|c|c|c|c|c|}
\hline Especialidade & $\begin{array}{c}\text { UFC } \\
\text { (pré- } \\
\text { higienização) }\end{array}$ & morg & $\begin{array}{c}\text { UFC } \\
\text { (pós- } \\
\text { higienização) }\end{array}$ & morg & dia/mês \\
\hline \multirow{24}{*}{ Médicos Cirurgia Geral } & 100.000 & SCN & 8.000 & SCN & 02/ago \\
\hline & 100.000 & SCN & 50.000 & SCN & 02/ago \\
\hline & 2.000 & BGN & 24.000 & SCN & 08/ago \\
\hline & 6.000 & S.AUREUS & 16.000 & SCN & 09/ago \\
\hline & 36.000 & SCN & 17.000 & SCN & 09/ago \\
\hline & 71.000 & SCN & 68.000 & SCN & 10/ago \\
\hline & 6.000 & SCN & 19.000 & SCN & 08/ago \\
\hline & 4.000 & S.aureus & 18.000 & S.aureus & \\
\hline & 1.000 & BGN & 11.000 & SCN & 30/ago \\
\hline & 32.000 & $\mathrm{SCN}$ & & & \\
\hline & 18.000 & $\mathrm{SCN}$ & 45.000 & $\mathrm{SCN}$ & $01 /$ set \\
\hline & 10.000 & SCN & 2.000 & SCN & $01 /$ set \\
\hline & $>100.000$ & SCN & $>100.000$ & SCN & $01 /$ set \\
\hline & $>100.000$ & $\mathrm{SCN}$ & 22.000 & SCN & $14 /$ set \\
\hline & NHC & & 30.000 & SCN & $21 /$ set \\
\hline & $>100.000$ & SCN & $>100.000$ & SCN & $21 /$ set \\
\hline & $>100.000$ & $\mathrm{SCN}$ & 5.000 & SCN & 03/out \\
\hline & 18.000 & SCN & 12.000 & $\mathrm{SCN}$ & 11/out \\
\hline & 90.000 & SCN & 59.000 & SCN & 31/out \\
\hline & $>100.000$ & $\mathrm{SCN}$ & $\mathrm{NHC}$ & & $24 /$ nov \\
\hline & $\mathrm{NHC}$ & & $\mathrm{NHC}$ & & $21 / \mathrm{dez}$ \\
\hline & 6.000 & $\mathrm{SCN}$ & 15.000 & SCN & 21/dez \\
\hline & 26.000 & SCN & $\mathrm{NHC}$ & & 21/dez \\
\hline & $\mathrm{NHC}$ & SCN & 12.000 & SCN & 08/jan \\
\hline
\end{tabular}

Legenda: UFC: Unidade Formadora de Colônias; $\mu$ org: microrganismo; SCN: Staphylococcus coagulase negativo (SCoN); BGN: bastonetes gram-negativos; Staphylococcus aureus: NHC: não houve crescimento.

Tabela 2. Contaminação das mãos após higienização por Médicos Anestesiologistas, Ortopedistas e Ginecologistas/Obstetras

\begin{tabular}{|c|c|c|c|c|c|}
\hline Especialidade & $\begin{array}{c}\text { UFC } \\
\text { (pré- } \\
\text { higienização) }\end{array}$ & moorg & $\begin{array}{c}\text { UFC } \\
\text { (pós- } \\
\text { higienização) }\end{array}$ & moorg & dia/mês \\
\hline \multirow{6}{*}{ Médicos Anestesiologistas } & 70.000 & SCN & 20.000 & $\mathrm{SCN}$ & 04/ago \\
\hline & 50.000 & SCN & 3.000 & SCN & 09/ago \\
\hline & 100.000 & SCN & 81.000 & SCN & 10/ago \\
\hline & 100.000 & $\mathrm{SCN}$ & 20.000 & $\mathrm{SCN}$ & 10/ago \\
\hline & 74.000 & SCN & 21.000 & $\mathrm{SCN}$ & 14/ago \\
\hline & 6.000 & SCN & 1.000 & SCN & $06 /$ set \\
\hline \multirow{6}{*}{ Médicos Ortopedistas } & 1.000 & SCN & 24.000 & SCN & 07/ago \\
\hline & 100.000 & SCN & 100.000 & SCN & 07/ago \\
\hline & 70.000 & SCN & 100.000 & SCN & 08/ago \\
\hline & 41.000 & SCN & 4.000 & SCN & 09/ago \\
\hline & 1.000 & SCN & 100.000 & S.aureus & 10/ago \\
\hline & 18.000 & S.aureus & 4.000 & $\mathrm{SCN}$ & 10/ago \\
\hline \multirow{3}{*}{$\begin{array}{c}\text { Médicos Ginecologistas- } \\
\text { Obstetras }\end{array}$} & $\mathrm{NHC}$ & - & 85.000 & $\mathrm{SCN}$ & 04/ago \\
\hline & 31.000 & $\mathrm{SCN}$ & $\mathrm{NHC}$ & - & 08/ago \\
\hline & $>100.00$ & $\mathrm{SCN}$ & $>100.000$ & $\mathrm{SCN}$ & 30/ago \\
\hline
\end{tabular}

Legenda: UFC: Unidade Formadora de Colônias; بorg: microrganismo; SCN: Staphylococcus coagulase negativo (SCoN),; BGN: bactérias gram-negativas; S. aureus: Staphylococcus aureus; NHC: não houve crescimento. 
Tabela 3: Contaminação das mãos após higienização por Médicos Residentes e Acadêmicos de Medicina

\begin{tabular}{|c|c|c|c|c|c|}
\hline Especialidade & $\begin{array}{c}\text { UFC } \\
\text { (pré- } \\
\text { higienização) }\end{array}$ & 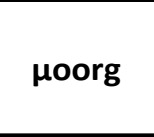 & $\begin{array}{c}\text { UFC } \\
\text { (pós- } \\
\text { higienização) }\end{array}$ & 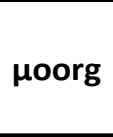 & dia/mês \\
\hline & 100.000 & $\mathrm{SCN}$ & 30.000 & SCN & 02/ago \\
\hline & 3.000 & $\mathrm{SCN}$ & 11.000 & $\mathrm{SCN}$ & 04/ago \\
\hline & $\mathrm{NHC}$ & - & 100.000 & $\mathrm{SCN}$ & 07/ago \\
\hline & 4.000 & $\mathrm{SCN}$ & 2.000 & $\mathrm{SCN}$ & 08/ago \\
\hline & 16.000 & $\mathrm{SCN}$ & 34.000 & $\mathrm{SCN}$ & 08/ago \\
\hline & $\mathrm{NHC}$ & - & 14.000 & SCN & 08/ago \\
\hline & 6.000 & S.aureus & 6.000 & SCN & 08/ago \\
\hline & 3.000 & $\mathrm{SCN}$ & 8.000 & SCN & 09/ago \\
\hline & 1.000 & $\mathrm{SCN}$ & 4.000 & $\mathrm{SCN}$ & 06/set \\
\hline Médicos Residentes e & $>100.000$ & $\mathrm{SCN}$ & 31.000 & $\mathrm{SCN}$ & 06/set \\
\hline \multirow[t]{10}{*}{ Acadêmicos de Medicina } & $>100.000$ & SCN & 12.000 & SCN & $14 /$ set \\
\hline & $>100.000$ & SCN & 9.000 & SCN & $14 /$ set \\
\hline & $>100.000$ & $\mathrm{SCN}$ & 87.000 & $\mathrm{SCN}$ & 31/out \\
\hline & 73.000 & SCN & 16.000 & SCN & $22 /$ nov \\
\hline & 51.000 & $\mathrm{SCN}$ & $\mathrm{NHC}$ & & $29 /$ nov \\
\hline & 10.000 & $\mathrm{SCN}$ & 2.000 & SCN & 22/mar \\
\hline & 43.000 & $\mathrm{SCN}$ & 1.000 & SCN & 22/mar \\
\hline & $>100.000$ & $\mathrm{SCN}$ & $>100.000$ & $\mathrm{SCN}$ & 22/mar \\
\hline & $\mathrm{NHC}$ & & $\mathrm{NHC}$ & & 22/mar \\
\hline & 41.000 & $\mathrm{SCN}$ & 4.000 & SCN & $22 / \mathrm{mar}$ \\
\hline
\end{tabular}

Legenda: UFC: Unidade Formadora de Colônias; $\mu$ org: microrganismo; SCN: Staphylococcus coagulase negativo; NHC: não houve crescimento.

Tabela 4: Contaminação das mãos após higienização por Enfermeiros

\begin{tabular}{|c|c|c|c|c|c|}
\hline Especialidade & $\begin{array}{c}\text { UFC } \\
\text { (pré- } \\
\text { higienização) }\end{array}$ & 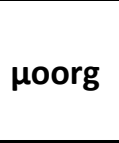 & $\begin{array}{c}\text { UFC } \\
\text { (pós- } \\
\text { higienização) }\end{array}$ & 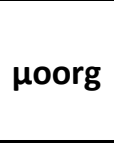 & dia/mês \\
\hline \multirow{10}{*}{ Enfermeiros } & 36.000 & $\mathrm{SCN}$ & 40.000 & SCN & 09/ago \\
\hline & 100.000 & SCN & 100.000 & SCN & 09/ago \\
\hline & 34.000 & SCN & 5.000 & SCN & 30/ago \\
\hline & 18.000 & SCN & 1.000 & SCN & 30/ago \\
\hline & $>100.000$ & $\mathrm{SCN}$ & 36.000 & SCN & 06/set \\
\hline & $>100.000$ & $\mathrm{SCN}$ & 26.000 & SCN & 11/out \\
\hline & $>100.000$ & $\mathrm{SCN}$ & $>100.000$ & $\mathrm{SCN}$ & 08/nov \\
\hline & 28.000 & $\mathrm{SCN}$ & 90.000 & $\mathrm{SCN}$ & 08/nov \\
\hline & 7.000 & $\mathrm{SCN}$ & 30.000 & $\mathrm{SCN}$ & 08/nov \\
\hline & 38.000 & $\mathrm{SCN}$ & 15.000 & SCN & $24 /$ nov \\
\hline
\end{tabular}

Legenda: UFC: Unidade Formadora de Colônias; $\mu$ org: microrganismo; SCN: Staphylococcus coagulase negativo (SCoN); BGN: bactérias gram-negativas; S. aureus: Staphylococcus aureus; NHC: não houve crescimento. 


\section{Considerações finais}

Foram encontrados três diferentes grupos de bactérias: Grupo Stafilococcus coagulase e Staphylococcus coagulase negativo ( $\mathrm{SCoN})$, Staphylococcus aureus e Bacilos gram negativo com predominância de maior contaminação no grupo dos médicos ortopedistas e acadêmicos,e menor contaminação no grupo de enfermeiros. Concluiu-se que a técnica de higienização das mãos não foi realizada de modo eficaz. Não houve um padrão de diminuição da Unidade Formadora de Colônias.

Os resultados dessa pesquisa revelaram a necessidade de uma sensibilização das equipes que atuam no centro cirúrgico para a prática da higienização das mãos. Como sugestão futura, que seja realizado o Teste T Student, para analisar se existe diferença significativa entre os momentos pré e pós-higienização das mãos.

O papel educativo é fundamental para sedimentar as bases de boas práticas, em conhecimentos teóricos e no desenvolvimento de habilidades e reforço. Toda a equipe de instituições de saúde e, em especial os profissionais da saúde, incluindo acadêmicos, durante seu período de formação prática, devem proporcionar uma assistência à saúde segura, evitando as infecções hospitalares em seu trabalho diário. Os programas de higienização das mãos devem incluir ações distintas, como a introdução de soluções alcoólicas, a educação e a motivação do pessoal, junto com a avaliação e assessoramento da qualidade da técnica da higienização das mãos.

A promoção da educação continuada sobre a higienização das mãos deve ser um foco permanente nos serviços de saúde, visando ao controle das infecções hospitalares, e que a responsabilidade não deve ser somente assumida pela Comissão de Controle de Infecção Hospitalar e, sim por todos os profissionais que integram o quadro de pessoal da instituição. Dessa forma, sugere-se utilização de métodos educativos multimodais e com um grupo de controle, para observar melhor o efeito dessas intervenções.

\section{Referências}

1. Brasil. Ministério da Saúde. Agência Nacional de Vigilância Sanitária. Higienização das mãos em serviços de saúde/ Agência Nacional de Vigilância Sanitária. Brasília: Anvisa, 2007.

2. Andrade GM. Infecção Hospitalar: mitos e verdades, velhos hábitos, novas atitudes. Brasília Méd. 2002; 39(1): 57-9. Disponível: http://www.ambr.com. br/revista/revista_39.pdf

3. Associação Paulista de Estudos e Controle de Infecção Hospitalar. Guia para higiene de mãos em serviços de assistência à saúde. São Paulo: APECIH, 2003

4. Barreto RASS, Rocha LO, Souza ACS, Tipple AFV, Suzuki K, Bisinoto AS. Higienização das mãos: a adesão entre os profissionais de enfermagem da sala de recuperação pós-anestésica. Rev. Eletr. Enf. 2009;11(2):334-40.
5. Brasil. Ministério da Saúde. Boletim Informativo do Ministério da Saúde. Programa de controle de infecção hospitalar. Lavar as mãos: Informações para profissionais de saúde. Brasília, 1989.

6. Larson E, Friedman P, Cohran J, Treston-Aurand J, Green S. Prevalence and correlates of skin damage on the hands of nurses. Heart Lung: J Acute Crit Care. 1997;26(5):404-12.

7. Brasil. Ministério da Saúde. Portaria MS nº. 2616 de 12 de maio de 1998. Estabelece as normas para o programa de controle de infecção hospitalar. Diário Oficial da União, 1998.

8. Neves ZCP, Tipple AFV, Souza ACS, Pereira MS, Melo DS, Ferreira LR. Higienização das mãos: o impacto de estratégias de incentivo à adesão entre profissionais de saúde de uma unidade de terapia intensiva neonatal. Rev Latino-Am Enferm. 2006;14(4):130-54.

9. Allegranzi B, Bischoff P, de Jonge S, Kubilay NZ, Zayed B, Gomes SM et al. WHO Guidelines Development Group. New WHO recommendations on preoperative measures for surgical site infection prevention: an evidencebased global perspective. Lancet Infect Dis. 2016 Dec;16(12):e276-e287

10. Primo MGB, Ribeiro LCM, Figueiredo LFS, Sirico SCA, Souza MA. Adesão à prática de higienização das mãos por profissionais de saúde de um Hospital Universitário. Rev. Eletr. Enf. [Internet]. 2010 abr./jun.;12(2):26671. Disponível em: http://dx.doi.org/10.5216/10.5216/ree.v12i2.7656.

11. Organização Mundial da Saúde (OMS). Diretrizes da OMS sobre higienização das mãos na assistência à saúde (versão preliminar avançada): Resumo. World Health Organization 2005.

12. Škodová M, Gimeno-Benítez A, Martínez-Redondo E, Morán-Cortés JF, Jiménez-Romano R, Gimeno-Ortiz A. Avaliação da qualidade da técnica de higiene das mãos em alunos de enfermagem e medicina em dois cursos de graduação. Rev. Latino-Am. Enfermagem. jul.-ago. 2015;23(4):708-17.

13. Belela-Anacleto ASC, Peterlini MAS, Pedreira MLG. Higienização das mãos como prática do cuidar: reflexão acerca da responsabilidade profissional. Rev Bras Enferm [Internet]. 2017 mar-abr;70(2):461-4. 